\title{
DTIC-BCNU-Cisplatin Regimen
}

National Cancer Institute

\section{Source}

National Cancer Institute. DTIC-BCNU-Cisplatin Regimen. NCI Thesaurus. Code C63784.

A regimen consisting of cisplatin, dacarbazine and carmustine used for the treatment of advanced-stage or metastatic malignant melanoma. 